International Journal of Current Advanced Research

ISSN: O: 2319-6475, ISSN: P: 2319 - 6505, Impact Factor: SJIF: 5.995

Available Online at www.journalijcar.org

Volume 6; Issue 3; March 2017; Page No. 2619-2625

DOI: http://dx.doi.org/10.24327/ijcar.2017.2625.0059

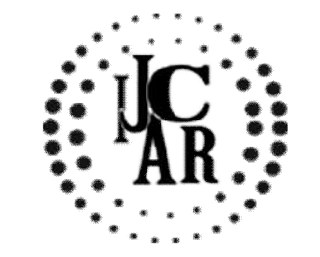

Research Article

\title{
EFFECT OF SURFACE POLISHING AND ORAL BEVERAGES ON THE SURFACE PROFILE AND COLOR STABILITY OF TWO COMPOSITE RESINS - IN VITRO
}

\section{Deepika Thosre Chandhok¹., Jasmeet Singh Chandhok²., Sanjyot Mulay ${ }^{3}$, Grishmi Niswade $^{4}{ }^{*}$, Jayashree Sajjanar ${ }^{5}$ and Arihant Bathiya ${ }^{6}$}

\author{
1,2Swargiya Dadasaheb Kalmegh Smruti Dental College and Hospital, Wanadongri road, Hingna, Nagpur- 441110, India \\ ${ }^{3}$ Dr. D. Y. Patil Dental College and Hospital, Pimpri, Pune - 411018, India \\ 4,5Swargiya Dadasaheb Kalmegh Smruti Dental College and Hospital, Wanadongri Road, Hingna, Nagpur- 441110, India
}

\section{A R T I C L E I N F O}

\section{Article History:}

Received $12^{\text {th }}$ December, 2016

Received in revised form $6^{\text {th }}$ January, 2017

Accepted $26^{\text {th }}$ February, 2017

Published online $28^{\text {th }}$ March, 2017

\section{Key words:}

Composite restorative materials, Discoloration, Finishing, Polishing, Spectrophotometer, Surface profilometer, CIE Lab system,

Scanning electron microscope

\begin{abstract}
A B S T R A C T
Background: Surface quality of dental restorations is an important factor in determining the success of particularly anterior restorations. Surface roughness is one of the major causes of external discoloration, excessive plaque accumulation, gingival irritation, secondary caries and poor or less than optimal aesthetics of the restored teeth. These consequences are closely related to the type of composite material and the finishing and polishing systems used.

Material and Methods: The surface profiles of 72 samples each of a Nanofilled (Z-350) and a Micro-hybrid (Esthet-X) composite resins were determined pre and post finishing and polishing with two different finishing and polishing systems viz. Aluminium oxide discs (Soflex), Fine \& extrafine grit aluminium oxide paste along with polishing discs and cones (Enhance) and Mylar strip was control. The samples from each group were further immersed in commonly consumed oral beverages viz. tea, coffee, cola and artificial saliva was the control for 30 days. The change in color for all the samples was determined using a Reflectance Spectrophotometer and CIELab system and post-immersion surface profile was determined using Profilometer and Scanning Electron Microscope.

Results: For both the composite resins Aluminium oxide finishing and polishing discs provided the smoothest surface as compared to fine grit aluminium oxide paste and Mylar strip. Coffee caused significant staining of composites followed by Tea; which was maximum after finishing and polishing with fine grit aluminium oxide paste. Cola was seen to cause a significantly rough composite surface as compared to other oral beverages. Micro-hybrid displayed more surface roughness and stainability as compared to Nanofilled composite resins.

Conclusion: The staining susceptibility of the composite resins may be attributed to their filler size and surface profile post finishing and polishing procedure. Coffee and tea can significantly discolor microhybrid as well as nanofilled composite resins.
\end{abstract}

Copyright $₫ 2017$ Grishmi Niswade. This is an open access article distributed under the Creative Commons Attribution License, which permits unrestricted use, distribution, and reproduction in any medium, provided the original work is properly cited.

\section{INTRODUCTION}

The esthetic quality of restoration may be as important to the mental health of patient as biological \& technical qualities of restoration are to his physical $\&$ dental health. ${ }^{1}$ Surface quality of dental restorations is an important factor in determining the success of particularly anterior restorations. ${ }^{2}$ Surface roughness is one of the major causes of external discoloration, and it is closely related to the type of composite material and the finishing and polishing systems used. Proper finishing and polishing are important aspects of clinical restorative procedures that enhances both the esthetics and the longevity of restoration. ${ }^{3}$

*Corresponding author: Grishmi Niswade, Swargiya Dadasaheb Kalmegh Smruti Dental College and Hospital, Wanadongri Road, Hingna, Nagpur- 441110, India excessive plaque accumulation, gingival irritation, secondary caries, patient discomfort and poor or less than optimal aesthetics of the restored teeth., ${ }^{2,3}$ The stainability of resin composite material is related to polymerization type, filler particle and type of staining agent. ${ }^{4}$ Commonly consumed oral beverages like tea, coffee and cola are also thought to be the major contributors to staining composites. ${ }^{5}$ Still one of the properties of the composite resins that have to pass the test to time is their color stability. ${ }^{6}$ Unacceptable color match is a primary reason for replacement of composite resin restorations. The newer microhybrid and nanofilled composite resins with improved mechanical properties have the advantage of more strength, better translucency and smoother surface finish thus providing an ideal material for anterior restorative purpose. The increasing consumption of beverages like Tea, Coffee and Aerated drinks and the growing use of 
composite restorative materials aroused the need for the current research.

Very few studies have been conducted to establish a relationship between surface roughness and stain resistance. Thus, the current article aims to discuss how two different types of composite resins with varying filler contents can interact with two polishing systems commonly used and various oral beverages consumed by the patient.

\section{MATERIALS AND METHODS}

A total of 144 composite discs of dimensions 8 X $2 \mathrm{~mm}$ were made from a custom made stainless steel mould. Of them, 72 specimens of a nanofilled composite [Z-350 A2 shade (3M)], and a micro-hybrid [Aesthet-X A2 shade (Dentsply)] each were fabricated.
$100 \%$ humidity for 24 hours at $37{ }^{\circ} \mathrm{C}$ in an incubator (DBK BOD, Model - DTC 96, Innovative Bacteriological Incubator). The 72 samples of each composite resin were then divided into 3 groups comprising of 24 samples each of aluminium oxide discs (Soflex- 3M), Fine grit aluminium oxide powder with glycerine in paste form along with polishing cones (Enhance- Dentsply) and Mylar strip (Dentsply) which was the control.

The pre-polishing surface roughness (Ral values) of each of the 144 specimens were measured using a Surface Profilometer $^{7}$ (Mitutoyo - ER-2001, Serial number GN5560) and the readings were recorded (Tables $3 \& 4$ ). (All readings were made with the instrument range selection set at 0 to $2 \mu \mathrm{m}$ and the cut off selector set at $0.8 \mathrm{~mm}$ ).

Table 1 Distribution of samples into various groups and sub-groups for nanofilled composite resin

\begin{tabular}{|c|c|c|}
\hline COMPOSITE RESIN & POLISHING SYSTEM & STAINING SOLUTION \\
\hline \multirow{12}{*}{$\begin{array}{l}\text { 1] Nanofilled composite } \\
\qquad \begin{array}{l}(\mathrm{Z}-350) \\
(\mathrm{n}=72)\end{array}\end{array}$} & \multirow{4}{*}{$\begin{array}{l}\text { A] Aluminium oxide discs } \\
\text { (Soflex) } \\
(n=24)\end{array}$} & a) Tea $(n=6)$ \\
\hline & & b) Coffee $(n=6)$ \\
\hline & & c) $\operatorname{Cola}(n=6)$ \\
\hline & & d) Artificial saliva (Control) $(n=6)$ \\
\hline & \multirow{4}{*}{$\begin{array}{l}\text { B] Fine \& extrafine grit aluminium oxide paste } \\
\text { along with polishing discs and cones (Enhance) } \\
\qquad(\mathbf{n}=\mathbf{2 4})\end{array}$} & a) $\operatorname{Tea}(n=6)$ \\
\hline & & b) Coffee $(n=6)$ \\
\hline & & c) Cola $(n=6)$ \\
\hline & & d) Artificial saliva (Control) $(n=6)$ \\
\hline & \multirow{4}{*}{$\begin{array}{c}\text { C] Mylar strip } \\
\text { (Control) }\end{array}$} & a) Tea $(n=6)$ \\
\hline & & b) Coffee $(n=6)$ \\
\hline & & c) $\operatorname{Cola}(n=6)$ \\
\hline & & d) Artificial saliva (Control) $(n=6)$ \\
\hline
\end{tabular}

Table 2 Distribution of samples into various groups and sub-groups for microhybrid composite resin

\begin{tabular}{|c|c|c|}
\hline COMPOSITE RESIN & POLISHING SYSTEM & STAINING SOLUTION \\
\hline \multirow[t]{12}{*}{ II] Micro-hybrid composite (Esthet-X) } & \multirow{4}{*}{$\begin{array}{l}\text { A] Aluminium oxide discs } \\
\text { (Soflex) }\end{array}$} & a) Tea $(n=6)$ \\
\hline & & b) Coffee $(n=6)$ \\
\hline & & c) Cola $(n=6)$ \\
\hline & & d) Artificial saliva (Control) $(n=6)$ \\
\hline & \multirow{4}{*}{$\begin{array}{l}\text { B] Fine \& extrafine grit aluminium oxide } \\
\text { paste along with polishing discs and cones } \\
\text { (Enhance) }\end{array}$} & a) Tea $(n=6)$ \\
\hline & & b) Coffee $(n=6)$ \\
\hline & & c) Cola $(n=6)$ \\
\hline & & d) Artificial saliva (Control) $(n=6)$ \\
\hline & \multirow{4}{*}{$\begin{array}{c}\text { C] Mylar strip } \\
\text { (Control) }\end{array}$} & a) Tea $(n=6)$ \\
\hline & & b) Coffee $(n=6)$ \\
\hline & & c) Cola $(n=6)$ \\
\hline & & d) Artificial saliva (Control) $(n=6)$ \\
\hline
\end{tabular}

Prior to finishing and polishing, all specimens were stored in Artificial saliva (Wet mouth - ICPA Health products Ltd.), at 


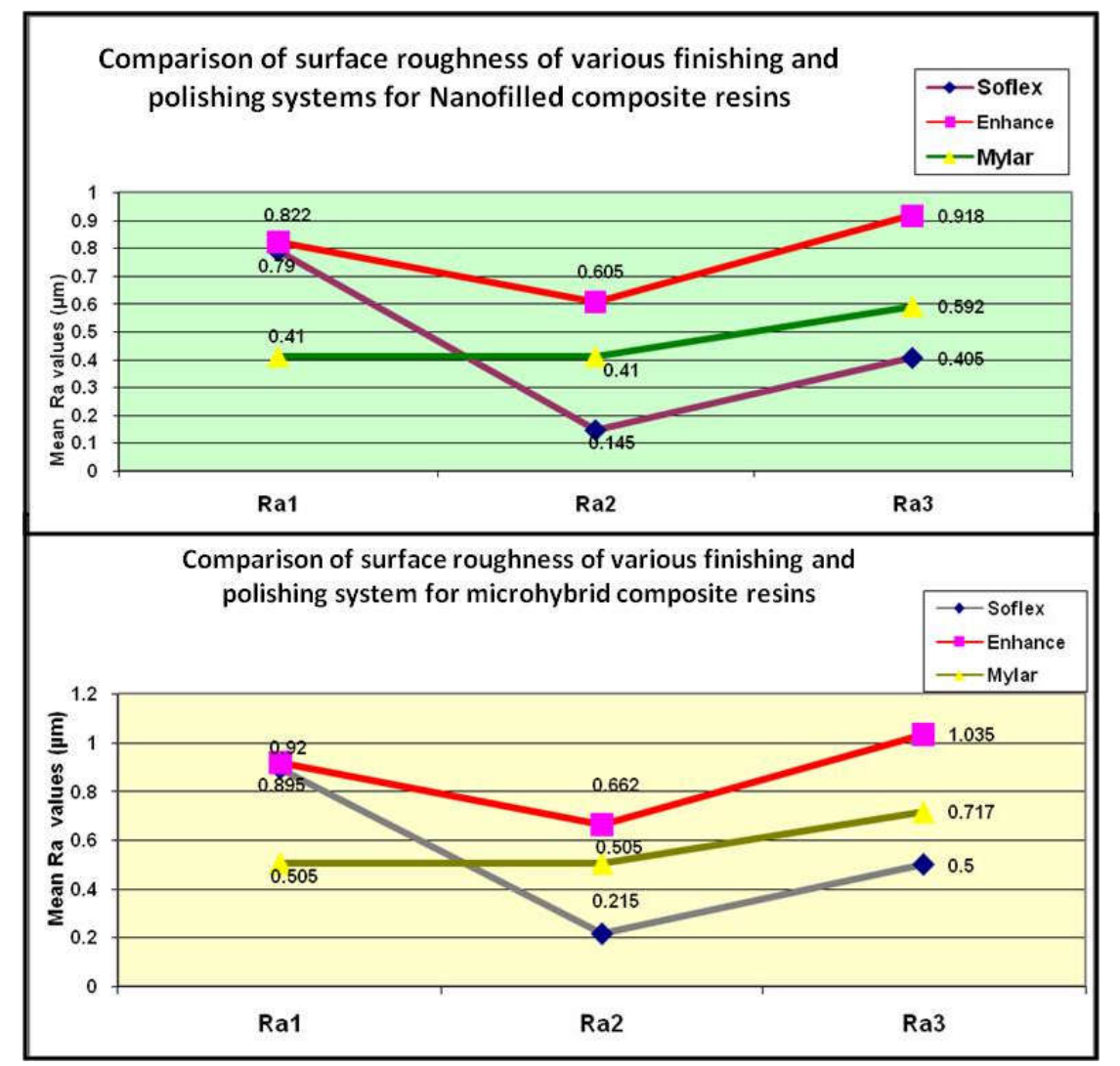

Figure 1: Comparison of surface profile of different finishing and polishing systems for nanofilled and microhybrid composite resins

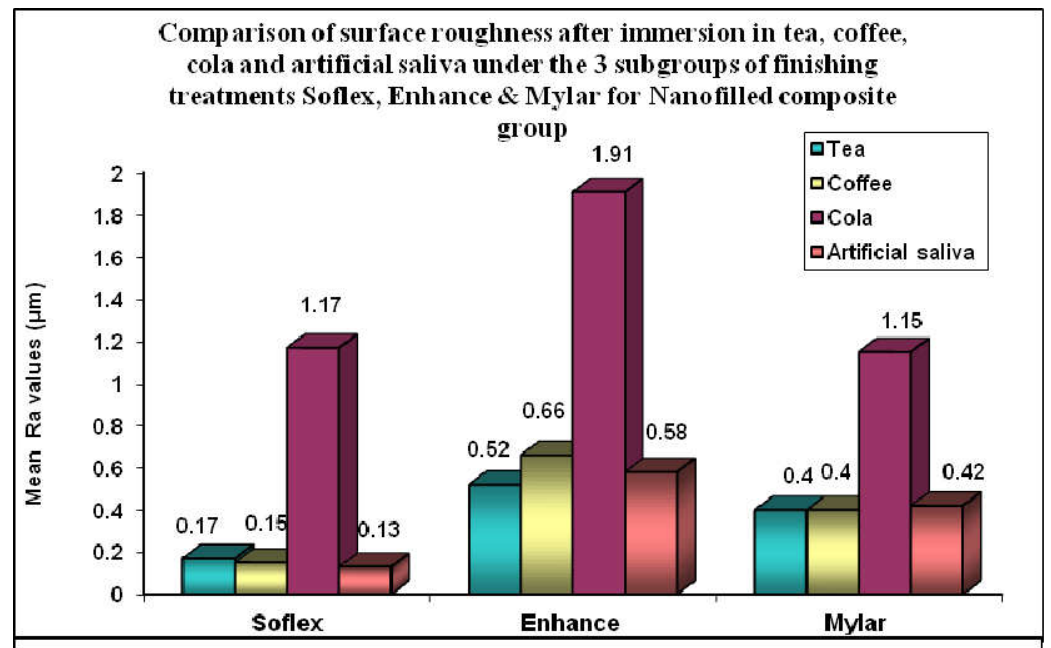

Comparison of surface roughness after immer sion in different beverages post finishing and polishing with different systems for Microhybrid composite group

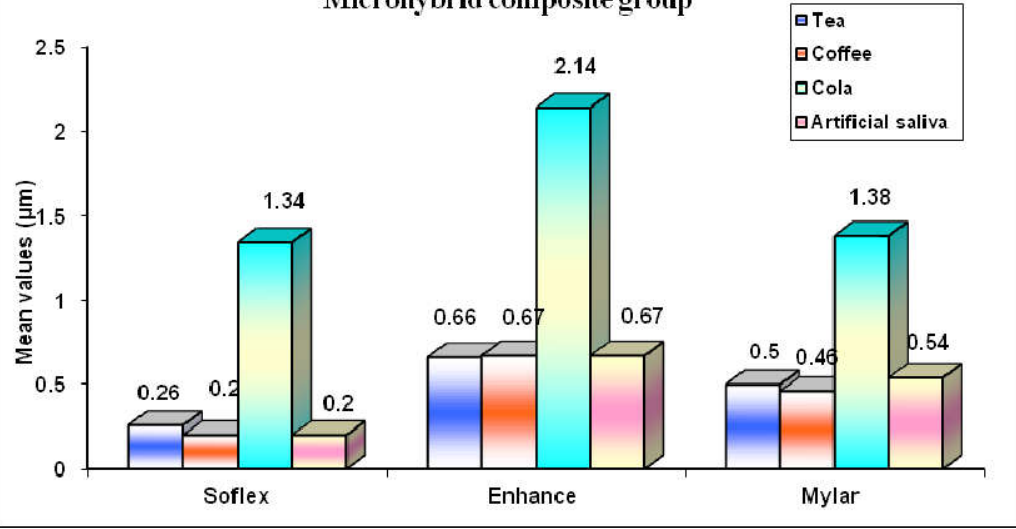

Figure 2 Comparison of surface profile for Microhybrid and Nanofilled composite groups after immersion in different beverages post finishing and polishing with different systems 
For finishing and polishing, each specimen was inserted back into the 8 X $2 \mathrm{~mm}$ stainless steel mould which was in turn inserted into a scaffold made up of dental stone to stabilize it. This whole assembly was then held onto a surveyor table, tightened with screws to make sure that the specimen did not move or rotate during the finishing and polishing procedure. Each specimen was polished and the next one was inserted into the mould. Specimens were finished and polished with a slow-speed hand piece and as directed by the manufacturer. The strokes (10 per disk) were standardized and applied with light pressure by a single operator. Each disk was discarded after single 'use. extra-fine pastes using cones and disks. They were used sequentially for $20 \mathrm{sec}$ each and strokes were standardized. The 24 samples each of both the composite resins were used as control and were not finished and polished after curing through a Mylar strip. The polished resin discs were washed, allowed to dry and kept in $100 \%$ humidity in Artificial saliva for 24 hours at $37{ }^{0} \mathrm{C}$ in an Incubator. The post-polishing surface roughness (Ra2 values) of the specimens was measured again using the same surface Profilometer with the previously mentioned settings. The readings were recorded (tables 3 \& 4).

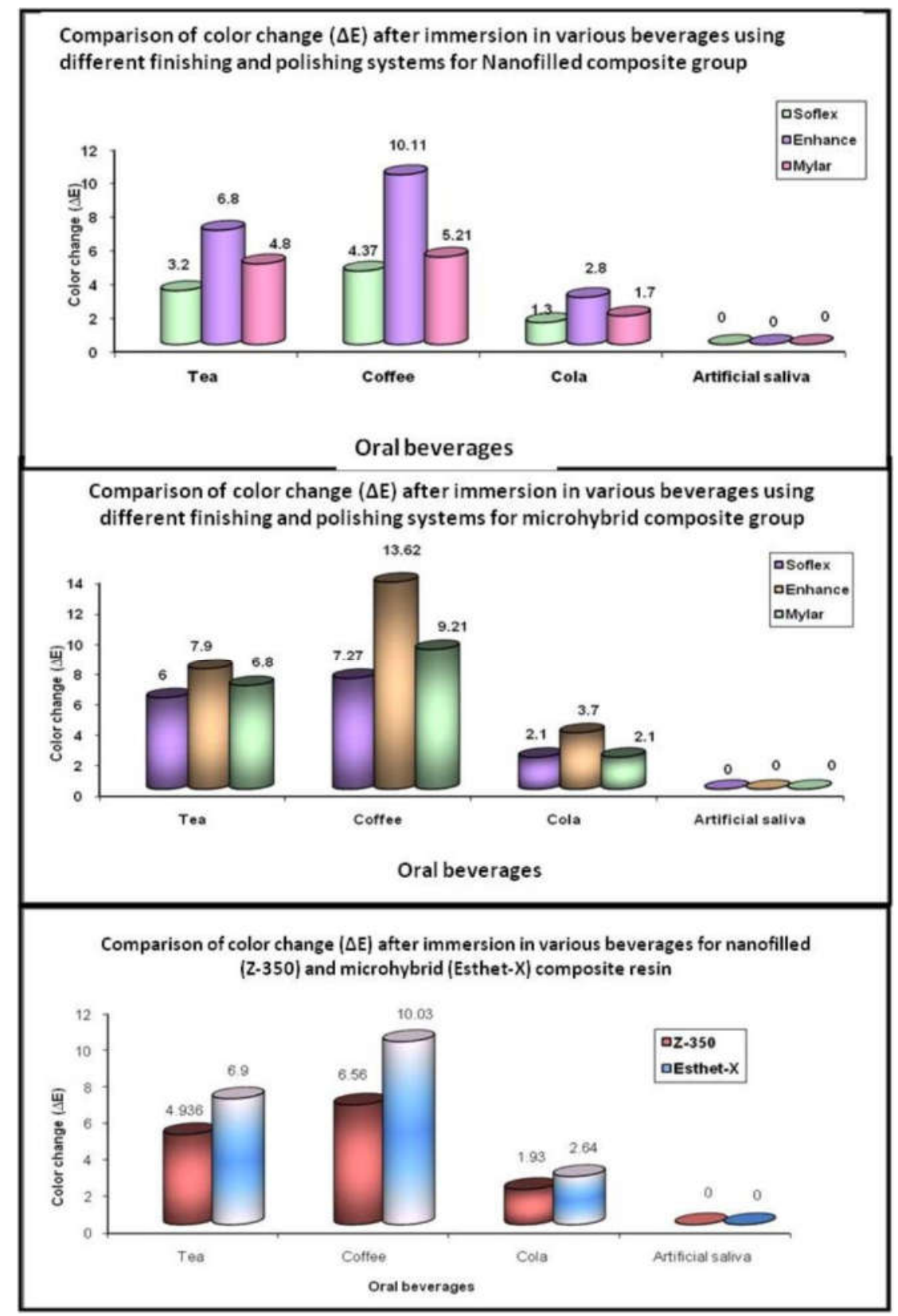

Figure 3 Inter and intra group comparison of color change $(\Delta \mathrm{E})$ after immersion in various beverages using different finishing and polishing systems for Nanofilled and Microhybrid composite groups

The 24 samples of each of the two composite resins in the first subgroup were finished and polished with aluminium oxide discs. The coarse, medium, fine and super fine grit disks were sequentially used for $20 \mathrm{sec}$ each. This was followed by finishing and polishing of the 24 samples each of both the composite resins using aluminium oxide fine and
For immersion of composite discs in oral beverages test solutions were prepared by adding 30 grams of Coffee powder (Nescafe) and 30 grams of Tea (Tajmahal) each into 1 liter of boiling distilled water. After 10 minutes of stirring, the solution was filtered through a filter paper. $250 \mathrm{ml}$ of milk 
and 50 grams sugar were added to both the solutions. Also $100 \mathrm{ml}$ Artificial saliva was added to Tea, Coffee and Cola (Pepsi) to simulate the oral conditions. All the samples in subgroups IA, IB, IC, IIA, IIB and IIC were further subdivided into 4 subgroups having 6 samples each and were immersed in Tea, Coffee, Cola and Artificial saliva (Control) (Tables 1\&2). The specimens were immersed in individual vials with $10 \mathrm{ml}$ solution each. All solutions were stored at 37 $\pm 1{ }^{\circ} \mathrm{C}$ in an incubator for a period of 30 days. Test solutions were changed after every 3 days.

After 30 days, the specimens were dried and placed one by one on the viewing port of the Reflectance Spectrophotometer (Ocean Optics, Model - HR4000, Serial number - HR4C2097, High resolution USB Fiber Optic Spectrophotometer) for color measurement. The readings were recorded by the CIE LAB system which is a uniform color space with coordinates for lightness, namely, white-black $\left(\mathrm{L}^{*}\right)$, redness-greenness $\left(a^{*}\right)$, and yellowness-blueness $\left(b^{*}\right)$.

The pre-emersion and post-emersion $\mathrm{L}^{*}, \mathrm{a}^{*}$, and $\mathrm{b}^{*}$ values of each specimen were measured 3 times ${ }^{8,9}$. The pre-emersion $\mathrm{L}^{*}, \mathrm{a}^{*}$, and $\mathrm{b}^{*}$ values were the subtracted from the postemersion $\mathrm{L}^{*}, \mathrm{a}^{*}$, and $\mathrm{b}^{*}$ values to get the final color change in all the 3 co-ordinates which was denoted by $\Delta \mathrm{L}^{*}, \Delta \mathrm{a}^{*}$, and $\Delta \mathrm{b}^{*}$.Color difference $\left(\Delta \mathrm{E}^{*}\right)$ was calculated from the mean $\Delta \mathrm{L}^{*}, \Delta \mathrm{a}^{*}$, and $\Delta \mathrm{b}^{*}$ values for each specimen using the formula 10,11

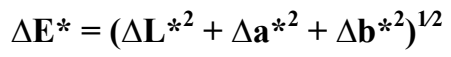

An average $\Delta \mathrm{E}$ value of the six samples present in the groups (a), (b), (c) and (d) of each subgroup A, B and C were calculated and recorded. (tables 1 and 2 ). Post-staining readings for surface profile ( $\mathrm{Ra} 3)$ were also recorded for all the samples of groups I and II using the same Surface Profilometer with the earlier mentioned parameters. Average readings of the six samples present in the subgroups $\mathrm{a}), \mathrm{b}$ ), c) and d) of each group A, B and C were recorded for Ra1, Ra2 and Ra3 (Figure land 2). The samples were examined under a scanning electron microscope (JEOL, JSM - 6360A Analytical Scanning Electron Microscope) and photomicrographs at a magnification of X 1000 were taken for a qualitative representation of surface topography as an adjunct to Profilometric measurements. The data was analyzed statistically using Student's Unpaired ' $t$ ' test.

\section{RESULT}

The results of the study can be summarized as follows:

\section{Nanofilled composite resin (Group I)}

Aluminium oxide disks caused the smoothest surface (Group IA- Mean Ra2 value $=0.145 \mu \mathrm{m}$ ) on nanofilled composite resin followed by Mylar strip (Group IC- Mean Ra2 value = $0.41 \mu \mathrm{m})$. Whereas Enhance finishing and polishing system caused the roughest surface (Group IB- Mean Ra2 value = $0.605 \mu \mathrm{m})$. Post-immersion in four oral beverages, Cola was seen to cause a significantly rough surface for group IA $($ Mean Ra3 value $=1.34 \mu \mathrm{m})$, IB $($ Mean Ra3 value $=1.91$ $\mu \mathrm{m})$ and $\mathrm{IC}($ Mean Ra3 value $=1.15 \mu \mathrm{m})$.

The change in color was maximum after immersion in Coffee for Group IA $(\Delta \mathrm{E}=4.37)$, IB $(\square \Delta \mathrm{E}=10.11)$ and IC $(\square \Delta \mathrm{E}=$ 5.21). This was followed by Tea for Group IA $(\Delta \mathrm{E}=3.2)$, IB $(\Delta \mathrm{E}=6.8)$ and IC $(\Delta \mathrm{E}=4.8)$. The color change obtained by
Cola was statistically insignificant, while Artificial saliva did not show any change in color.

\section{Microhybrid composite (Group II)}

Soflex finishing and polishing system caused the smoothest surface (Group IIA- Mean Ra2 value $=0.215 \mu \mathrm{m}$ ) on Microhybrid composite resin followed by Mylar strip (Group IIC- Mean Ra2 value $=0.505 \mu \mathrm{m})$. Whereas Enhance finishing and polishing system caused the roughest surface (Group IIB- Mean Ra2 value $=0.662 \mu \mathrm{m}$ ). Post-immersion in four oral beverages, Cola was seen to cause a significantly rough surface for group IIA (Mean Ra3 value $=1.34 \mu \mathrm{m}$ ), IIB $($ Mean $\mathrm{Ra3}$ value $=2.14 \mu \mathrm{m})$ and IIC $($ Mean $\mathrm{Ra3}$ value $=1.38$ $\mu \mathrm{m})$.

The change in color was maximum after immersion in Coffee for Group IIA ( $\Delta \mathrm{E}=7.27)$, IIB $(\square \Delta \mathrm{E}=13.62)$ and IIC $(\square \Delta \mathrm{E}$ $=9.21)$. This was followed by Tea for Group IIA $(\Delta \mathrm{E}=6.0)$, IIB $(\Delta \mathrm{E}=7.6)$ and IIC $(\Delta \mathrm{E}=6.8)$. The color change obtained by Cola was statistically insignificant, while Artificial saliva did not show any change in color. On comparing the two composite resins, nanofilled (Group I) showed a smoother surface than Microhybrid (Group II) composite and also the color change after immersion in various oral beverages was lesser for nanofilled composite resin (figure 3). The results can be summarized as follows:

- Finishing and polishing system with aluminium oxide discs (Soflex) provided the smoothest surface followed by Mylar strip and Fine \& extrafine grit aluminium oxide paste along with polishing discs and cones (Enhance) for both Nanofilled and Microhybrid composite resins.

- Cola was seen to cause a significantly rough composite surface as compared to other oral beverages. Tea, Coffee and Artificial saliva did not cause any significant change in the surface profile of both the composite resins.

- Coffee caused maximum staining followed by Tea for both the composite resins. Cola caused very minimal staining of samples which was statistically insignificant.

- The Microhybrid composite resin displayed more surface roughness and stainability than Nanofilled composite resin irrespective of the finishing and polishing system used.

\section{DISCUSSION}

The prevalence of beverages like Tea, Coffee and Aerated drinks and the growing use of composite restorative materials aroused the need for the current research. To simulate the clinical discoloration potential of the composites an accelerated lab test was given by Asmussen $(1983)^{3}$ which stated that the color changes produced in composite resins by storing for one month was well correlated with color change obtained after 12 months at $37^{\circ} \mathrm{C}$ in oral cavity. In many in vitro studies, the immersion period is typically four weeks or more in order to achieve a cumulative staining effect and obtain distinct results. ${ }^{3,12}$

In the present study the Soflex finishing and polishing system produced the smoothest surface due to the ability of aluminum oxide impregnated discs to cut the filler particles and matrix equally. Also, due to the available sequence of 
Soflex disks with each subsequent disk containing smaller sizes of impregnated aluminium oxide particles, it causes gradual removal of the surface irregularities leading to a smoother surface profile. ${ }^{13}$ Whereas, the Enhance finishing and polishing system with a composition of Polymerized Urethane Dimethacrylate Resin, Aluminum oxide, Silicon dioxide produced the roughest surface may be due to its inability to equally cut filler and matrix. The use of a single disk inspite the use of two polishing pastes does not seem to satisfactorily smoothen the composite resin surface may be due to the lack of sequential removal of surface irregularities as seen in the Soflex system. ${ }^{13}$

According to many authors like Meserret Baseren (2004) ${ }^{14}$, St-Georges AJ, Bolla M et al (2005) ${ }^{15}$, Sarac D, Sarac YS et al (2006) ${ }^{16}$ the composite samples cured under the Mylar strip provided the smoothest surface as compared to the finishing and polishing systems. Nevertheless, as certain studies have shown, the surface layer, which is rich in resin, needs to be eliminated; thus finishing and polishing is indispensable. ${ }^{3}$

The composition of the two composite resins used in the present study is as follows. The nanofilled composite resin contains BIS-GMA, BIS-EMA and UDMA with small amounts of TEGDMA. The filler contains a combination of a non-agglomerated, $20 \mathrm{~nm}$ nanosilica filler, and loosely bound agglomerated zirconia / silica nanocluster, consisting of agglomerates of primary zirconia/silica particles with size of $5-20 \mathrm{~nm}$ fillers. The cluster particle size range is 0.6 to 1.4 microns.

While, Microhybrid composite contains Bis-GMA, Bis-EMA and TEGDMA. The filler combination consists of barium fluoro alumino boro silicate glass with average filler particle size of $0.6-0.8$ microns with a narrow particle size distributions of $0.02-2.5$ microns. The silicon dioxide nanofiller is in the range of 10 to $20 \mathrm{~nm}$. Thus, nanofilled composite resins provided a smoother surface than Microhybrid probably due to the varying types, size and distribution of filler particles. ${ }^{17,} 18$ The results of this study revealed that that Cola caused considerable increase in surface roughness of composite resins. These results are similar to those reported by Neamat Abu-bakr, Linlin Han, Akira Okamoto (2000) ${ }^{19}$, Badra VV, Faraoni JJ, Ramos RP (2005) ${ }^{20}$ and Patrícia Petromilli, Nordi Sasso Garcia; Elídio Rodrigues Neto $(2008)^{21}$. This result can be attributed to the composite resins susceptibility to chemical erosion of the resin matrix due to carbonated drinks having low $\mathrm{pH}$, hydrolytic breakdown of filler particles and chemical degradation of silane agent, which can further be responsible for their discoloration. ${ }^{19}$

In the present study Coffee caused the maximum staining and the color change $(\Delta \mathrm{E})$ recorded after immersion in Coffee was highly significant as compared to Tea and Cola. Tea also caused significant staining but the color change $(\Delta \mathrm{E})$ recorded was lesser than that of Coffee. Discoloration by Tea might be due to absorption of tannins into the material surface. On the other hand, higher discoloration by Coffee might be due to both adsorption and absorption of colorants like caffiene ${ }^{12}$. This absorption and penetration of colorants into the organic phase of the material were probably due to compatibility of the polymer phase with the yellow colorants of Coffee. ${ }^{19}$
Also, in the present study, Cola caused slight color change $(\Delta \mathrm{E})$ of the composite samples but it was not significant. The extremely low $\mathrm{pH}$ of Cola (approximately 2) negatively affects the wear resistance of composite materials and can be a contributing factor for change in the color characteristics of the materials. Cola gains its color through the addition of caramel color. Caramel exhibits colors ranging from pale yellow to brown. ${ }^{11}$

The staining of samples due to Tea and Coffee might be enhanced due to the sticky effect of sugar on the staining of the beverages. Ahmet Umut Guler, Fikret Yilmaz, Tolga Kulunk, $(2005)^{9}$ reported that the presence of sugar in Coffee and Tea increased the color difference compared to Coffee or Tea without sugar for light-polymerized microhybrid composite resins.

Artificial saliva was kept as a control to simulate the in-vivo conditions as performed in the study by Badra VV, Faraoni JJ, Ramos RP et al in 2005. ${ }^{21}$ When composite resins were immersed in artificial saliva, the color differences were imperceptible and clinically acceptable. This observation confirms that saliva or water sorption by itself did not alter the color of composites to a considerable extent ${ }^{21}$. It is quite evident that more the surface roughness exhibited by the composite resin, more will be its ability to discolor the composite. ${ }^{2}$ So also in this study it was observed that Enhance finishing and polishing system exhibited the greatest surface roughness as well as staining followed by Mylar strip, while Soflex system exhibited the least. These results are in contrary to the study done by Uctasli MB et al in $2007 .^{3}$

Also when the composite resins were compared, the Microhybrid composite exhibited more surface roughness and thus stained more than the nanofilled in all subgroups. ${ }^{22,23}$ The staining susceptibility of the composite resins may be attributed to their surface profile and is directly proportional to the increase in their surface roughness. Surface roughness is a critical factor that influences the clinical behavior of dental restorations. Irregular surface texture of composite resins can lead to gingival irritation, surface staining, plaque accumulation, and secondary caries. ${ }^{23,}{ }^{24}$ According to the present study, Soflex composite finishing and polishing system would provide a better clinical outcome due to reduction in surface roughness demonstrated as compared to Mylar strip and Enhance finishing and polishing system. The clinical co-relation of the study results depends on how much color change $(\Delta \mathrm{E})$ is considered perceptible. ${ }^{9,23}$

It has been documented that if $\Delta \mathrm{E}<1$ is not considered perceptible to most subjects with normal color vision. ${ }^{23,24}$ Also, it has been claimed that under clinical conditions in the mouth, color differences with corresponding $\Delta \mathrm{E}$ values lower than 3.3 are acceptable in clinical dentistry ${ }^{9}$. In the current study, the $\Delta \mathrm{E}$ values of Tea and Coffee groups exceeded well above 3.3 while most of the values of the Cola group did not, proving that Tea and Coffee can cause significant discoloration of resin composites. The results obtained are in accordance with the study conducted by R Veena Kumari, Hema Nagaraj et al in $2015 .^{23}$

Contrary to the manufactures recommendations to use the corresponding finishing and polishing system for a particular composite brand, it was found in the present study that the 
Soflex system produced a smoother surface while Enhance produced a comparatively rougher surface on both the Nanofilled and Microhybrid composite resins. ${ }^{14}$ Thus it is the actual evaluation of the material and the clinical experience which should be taken into account while selecting a particular material or modality. This should be coupled with appropriate instructions to the patient, which in this case would be to avoid excessive consumption of Coffee and Tea after placement of an anterior composite restoration. ${ }^{23}$

The rapidly increasing consumption of beverages like Tea, Coffee and Aerated drinks and the growing use of composite restorative materials necessitated the need for the current research. Most studies on stain resistance of dental restorative materials have been conducted on specimens that were not polished or all polished with the same polishing system. ${ }^{6,9,12}$ However, different materials attain different surface profile when polished with the same system.

\section{References}

1. Anusavise, Kenneth J. Skinner's Science of Dental materials. $9^{\text {th }}$ edn. 1991 , W. B. Saunders publication.

2. $\mathrm{Lu} \mathrm{H}$, Roeder LB, Powers JM. Effect of surface roughness on stain resistance of dental resin composites. J Esthet Restor Dent. 2005;17: 102-109

3. Uctasli MB, Arisu HD, Omurlu H, Eliguzeloglu E, Ozcan S, Ergun G. The effect of different finishing and polishing systems on the surface roughness of different composite restorative materials. J Contemp Dent Pract. 2007 Feb 1;8(2):89-96.

4. Turssi CP, Saad JR, Duarte SL Jr, Rodrigues AL Jr. Composite surfaces after finishing and polishing techniques. Am J Dent. 2000 Jun;13(3):136-8

5. Villalta P, Lu H, Okte Z, Garcia-Godoy F, Powers JM. Effects of staining and bleaching on color change of dental composite resins. J Prosthet Dent. 2006 Feb;95(2):137-42

6. Gupta R, Parkash H, Shah N, Jain V. A spectrophotometric evaluation of color changes of various tooth colored veneering materials after exposure to commonly consumed beverages. JIPS, Feb 2005; 5 (2 ) 72-78

7. Rutu Gedik, Feridun Hurmuzlu, Akin Coikun. Surface roughness of new microhybrid resin-based composites. $J$ Am Dent Assoc. 2005, Vol 136, No 8, 1106-1112.

8. Ronald Goldstein. Final Finishing of Composites and Laminates. Contemporary Esthetic Dentistry 1996; Vol. 2, No. 2.

9. Guler AU, Yilmaz F, Kulunk T, Guler E, Kurt S. Effects of different drinks on stainability of resin composite provisional restorative materials. J Prosthet Dent. 2005 Aug;94(2):118-24.

10. Stavros A. Yannikakis, Alcibiades J. Zissis, Gregory L. Polyzois, Chrysseis Caroni. Color stability of provisional resin restorative materials. The Journal of Prosthetic Dentistry, 1998, Vol. 80 no. 5, 533 - 9.

11. Temel Koksal and Idil Dikbas. Color Stability of Different Denture Teeth Materials against Various Staining Agents. Dental Materials Journal 27(1) : 139-144, 2008
12. Omata Y, Uno S, Nakaoki Y, Tanaka T, Sano H, Yoshida S, Sidhu SK. Staining of hybrid composites with coffee, oolong tea, or red wine. Dent Mater J. 2006 Mar;25(1):125-31.

13. Ahmed Mohammed Hassan, Sameh Mahmoud Nabih, Hossam Mohammed Mossa, Kusai Baroudi. The effect of three polishing systems on surface roughness of flowable, microhybrid, and packable resin composites. J Int Soc Prev Community Dent. 2015 May-Jun; 5(3): 242-247.

14. Baseren M. Surface roughness of nanofill and nanohybrid composite resin and ormocer-based toothcolored restorative materials after several finishing and polishing procedures. J Biomater Appl. 2004 Oct;19(2):121-34.

15. St-Georges AJ, Bolla M, Fortin D, Muller-Bolla M, Thompson JY, Stamatiades PJ. Surface finish produced on three resin composites by new polishing systems. Oper Dent. 2005 Sep-Oct;30(5):593-7.

16. Sarac D, Sarac YS, Kulunk S, Ural C, Kulunk T. The effect of polishing techniques on the surface roughness and color change of composite resins. J Prosthet Dent. 2006 Jul;96(1):33-40.

17. Dietschi D, Campanile G, Holz J, Meyer JM. Comparison of the color stability of ten new-generation composites: an in vitro study. Dent Mater. 1994 Nov;10(6):353-62.

18. Reis AF, Giannini M, Lovadino JR, Ambrosano GM. Effects of various finishing systems on the surface roughness and staining susceptibility of packable composite resins. Dent Mater. 2003 Jan;19(1):12-8.

19. Neamat Abu-bakr, Linlin Han, Akira Okamoto. Changes in the mechanical properties and surface texture of compomer immersed in various media. The Journal of Prosthetic Dentistry, 2000, vol 84 no. 4

20. Badra VV, Faraoni JJ, Ramos RP, Palma-Dibb RG. Influence of different beverages on the microhardness and surface roughness of resin composites. Oper Dent. 2005 Mar-Apr;30(2):213-9.

21. Patrícia Petromilli, Nordi Sasso Garcia; Elídio Rodrigues Neto. Influence of surface sealant on the translucency of composite resin: effect of immersion time and immersion media. Mat. Res. June 2008 vol.11 no. 2 .

22. C Meena Kumari, K Manohar Bhat, Rahul Bansal. Evaluation of surface roughness of different restorative composites after polishing using atomic force microscopy. Journal of Conservative dentistry, 2016 ; Vol 19 (1): 56-62

23. R Veena Kumari, Hema Nagaraj, Kishore Siddaraju, and Ramya Krishna Poluri. Evaluation of the Effect of Surface Polishing, Oral Beverages and Food Colorants on Color Stability and Surface Roughness of Nanocomposite Resins. J Int Oral Health. 2015 Jul; 7(7): 63-70.

24. Maiara Justo Polli, Guilherme Anziliero Arossi. Effect of finishing and polishing on the color stability of composite resin immersed in staining solutions. Journal of Dental research and review. 2015; 2(3): 120 $-126$ 